\title{
Comparing titanium elastic nailing and plate osteosynthesis in treating both bone diaphyseal fractures of forearm in children
}

\author{
Debanga S. Barua, Anuj Joon*, Vaisakh A., Tirupati S. Shirdinayak, Hari K. N. G., Abhijit Das
}

Department of Orthopedics, Assam Medical College and Hospital, Dibrugarh, Assam, India

Received: 02 July 2021

Accepted: 13 August 2021

*Correspondence:

Dr. Anuj Joon,

E-mail: anuj.joon@gmail.com

Copyright: ( $)$ the author(s), publisher and licensee Medip Academy. This is an open-access article distributed under the terms of the Creative Commons Attribution Non-Commercial License, which permits unrestricted non-commercial use, distribution, and reproduction in any medium, provided the original work is properly cited.

\section{ABSTRACT}

Background: The present study aimed to compare the outcome of fixation of diaphyseal fractures of both bones of forearm using plate osteosynthesis (PO) and titanium elastic nail (TEN).

Methods: This comparative non-randomized clinical trial was done on children aged 5 to 15 years, with diaphyseal fractures of both bone forearm fractures, operated and managed at the department of orthopedics, Assam Medical College and Hospital, Dibrugarh. Intra- and post-operative findings were compared between PO and TEN group patients.

Results: Duration of hospital stay was significantly lower in patients in the TEN group (44.75 \pm 6.38 minutes) as compared to those in the PO group $(69.71 \pm 5.91$ minutes $)$, p value $<0.01$. Similarly, duration of hospital stay was significantly lower in patients in the TEN group (5.01 \pm 0.67 days) as compared to those in the PO group (8.32 \pm 1.44 days), $\mathrm{p}$ value $<0.05$. Based on price criteria, $80 \%$ of the patients in the PO group and $85 \%$ in TEN group had excellent functional outcome. Radiological union time, maximum radial bow and location of maximal radial bow were found to be statistically similar in the two groups. Complication rate was similar in the two study groups.

Conclusions: Based on the results of the present study, we conclude that both PO and TEN are be safely performed in children with diaphyseal both bone forearm fractures. With comparable functional and radiological outcomes, future studies are required before one technique can be recommended over the other.

Keywords: Both-bone forearm fracture, Intramedullary nailing, Open reduction, Internal fixation, Pediatrics

\section{INTRODUCTION}

Both-bone forearm fractures account for approximately $4 \%$ of all pediatric fractures and one fourth of all pediatric upper extremity long-bone fractures. ${ }^{1}$ The most common mechanism of injury is a fall onto an outstretched hand. ${ }^{2}$ Diaphyseal forearm fractures account for the most common open fractures of the upper extremity and the most common location of re-fractures in the paediatric population. ${ }^{3}$ Fractures at young age which are close to physis and in the plane of maximal joint motion have the highest chance of remodelling. A systematic review demonstrated that open reduction and internal fixation (ORIF) with plating is a common treatment technique for stabilizing diaphyseal both bone forearm fractures. ${ }^{4}$
Plating has been associated with fixation, adequate joint reduction and good to excellent functional outcomes. ${ }^{5}$ However, clinically it has been shown to cause soft tissue and neurovascular injury and infection after plate removal. ${ }^{6}$ As an alternative, intra-medullary nailing was developed to overcome some these disadvantages. ${ }^{7}$ By reducing soft tissue damage, the cosmesis tends to improve by the use of nailing. In addition, the reduced operative time and ease with which the implant can be removed, makes nailing a popular choice among surgeons and patients. ${ }^{8}$ However, studies have shown higher rate of nonunion with intramedullary nailing. ${ }^{9}$ The present study aimed to compare the outcome of fixation of diaphyseal fractures of both bones of forearm using plate osteosynthesis (PO) and titanium elastic nail (TEN). 


\section{METHODS}

\section{Study design and sampling}

This comparative non-randomized clinical trial was done on children aged 5 to 15 years, with diaphyseal fractures of both bone forearm fractures, operated and managed at the department of orthopedics, Assam Medical College and Hospital, Dibrugarh from January 2019 till December 2019. We included children aged 5 to 15 years, with irreducible and unstable diaphyseal fractures of both bones of forearm. Comminuted and segmental fractures were included as well. We excluded cases with open fractures, Montaggia fractures, Galleazi fractures, pathological fractures, fractures with neurovascular injuries, single bone fractures and those unfit or not willing to undergo surgery. The parents of the children eligible to participate in the study were explained the purpose of the study. Written parental consent was obtained for patients aged less than 7 years. For those aged 7 to 11 years, oral assent of the child in presence of parent or legally authorized representative was obtained. For children more than 11 years, written assent of the child was obtained. The study was approved by the institutional ethics committee before patients were enrolled in the study.

An equal number of patients (20 each) were operated using PO or TEN. The allocation was done non-randomly, but after detailed discussion between parents and the operating surgeon.

\section{Data collection and data analysis}

Using a pre-designed semi-structured study proforma, demographic information of the patients like age and gender were noted. The mode of injury, side of injury and site of injury were noted in all cases. For site, the forearm was divided into proximal, middle and distal thirds. Fractures were classified based on the Arbeitsgemeinschaft für osteosynthesefragen/orthopedic trauma association (AO/OTA) classification of diaphyseal fractures..$^{10}$ Operative notes were checked for the duration of surgery. Duration of hospital stay was also noted for all patients. Functional outcome was assessed using price index. ${ }^{11}$ Preoperative and latest follow-up standard anteroposterior (AP) and lateral radiographs of the forearm were reviewed. Restoration of radial bow was evaluated on the latest follow-up antero-posterior X-rays using the method described by Firl and Wunsch. In this the magnitude and location of the maximum radial bow is calculated. These values were compared with the normal values of $7.21 \pm 1.03 \%$ for bow magnitude and $60.39 \pm 3.74 \%$ for bow location in children. ${ }^{12}$ Complications were noted for all the patients. The data were described as means for quantitative data and frequency distribution for qualitative data. Means were compared using student's t test and qualitative data were compared using chi-square. A p value of less than 0.05 was considered as statistically significant.

\section{RESULTS}

There were 20 patients in each study group. The mean age of the patients in PO and TEN groups was $10.95 \pm 2.35$ and $10.40 \pm 2.41$ ( $\mathrm{p}$ value $=0.47$ ). It was found that fall was the cause of injury in $65 \%$ and road traffic accident in $35 \%$ in both the study groups (Table 1). Left side was involved in $40 \%$ in PO group and $50 \%$ in TEN group ( $\mathrm{p}$ value $=0.75$ ). Based on AO/OTA classification, 60\% in fractures in either of the study group were of 22A3.2 type. Middle third of forearm was the most common site of fracture $(70 \%$ in either study group). Duration of hospital stay was significantly lower in patients in the TEN group (44.75 \pm 6.38 minutes) as compared to those in the PO group $(69.71 \pm 5.91$ minutes), $\mathrm{p}$ value $<0.01$. Similarly, duration of hospital stay was significantly lower in patients in the TEN group (5.01 \pm 0.67 days) as compared to those in the PO group (8.32 \pm 1.44 days), p value $<0.05$. Based on price criteria, $80 \%$ of the patients in the PO group and $85 \%$ in TEN group had excellent functional outcome (Table 2). None of the patients had poor outcome and fair outcome was observed in one case in the PO group. Radiological union time, maximum radial bow and location of maximal radial bow were found to be statistically similar in patients in the two study groups. Table 3 compares the various complications among patients in PO and TEN group. Infection rate was similar in the two study groups $(10 \%$ each). There was one case of neuropraxia in the PO group.

Table 1: Comparison of baseline and intra-operative details of the patients.

\begin{tabular}{|llll|}
\hline Variables & Plate osteosynthesis $(\mathbf{n = 2 0})$ & Titanium elastic nail (n=20) & P value \\
\hline Age (years) & $10.95 \pm 2.35$ & $10.40 \pm 2.41$ & 0.47 \\
\hline Gender $(\%)$ & & & NA \\
\hline Female & $6(30)$ & $6(30)$ & $14(70)$ \\
\hline Male & $14(70)$ & & NA \\
\hline Mode of injury (\%) & $13(65)$ & $13(65)$ & $7(35)$ \\
\hline Fall & $7(35)$ & & 0.75 \\
\hline Road traffic accident & & $10(50)$ & $10(50)$ \\
\hline Side of injury $(\%)$ & $8(40)$ & & \\
\hline Left & $12(60)$ & & \\
\hline Right & & & \\
\hline
\end{tabular}




\begin{tabular}{|llll|}
\hline Variables & Plate osteosynthesis $(\mathbf{n = 2 0 )}$ & Titanium elastic nail $(\mathbf{n = 2 0 )}$ & P value \\
\hline AO/OTA classification $(\%)$ & & & \\
\hline $22 \mathrm{~A} 3.1$ & $2(10)$ & $3(15)$ & \\
\hline $22 \mathrm{~A} 3.2$ & $12(60)$ & $12(60)$ & \\
\hline $22 \mathrm{~A} 3.3$ & $4(20)$ & $3(15)$ & \\
\hline $22 \mathrm{~B} 3.1$ & $1(5)$ & $1(5)$ & \\
\hline $22 \mathrm{~B} 3.2$ & $1(5)$ & $1(5)$ & 0.81 \\
\hline Site of injury (\%) & $2(10)$ & $3(15)$ & \\
\hline Proximal third & $14(70)$ & $14(70)$ & $<0.01$ \\
\hline Middle third & $4(20)$ & $3(15)$ & $<0.05$ \\
\hline Distal third & $69.71 \pm 5.91$ & $44.75 \pm 6.38$ \\
\hline Duration of surgery (minutes) & $8.32 \pm 1.44$ & $5.02 \pm 0.67$ & \\
\hline Hospital stay (days) & & & \\
\hline
\end{tabular}

Table 2: Comparison of functional and radiological outcomes of the patients.

\begin{tabular}{|llll|}
\hline \multicolumn{1}{|l}{$\begin{array}{l}\text { Variables } \\
\text { Price criteria (\%) }\end{array}$} & Plate osteosynthesis $(\mathbf{n = 2 0 )}$ & Titanium elastic nail $(\mathbf{n = 2 0})$ & P value \\
\hline Excellent & $16(80)$ & $17(85)$ & \\
\hline Good & $3(15)$ & $3(15)$ & 0.59 \\
\hline Fair & $1(5)$ & $0(0)$ & \\
\hline Poor & $0(0)$ & $0(0)$ & 0.55 \\
\hline Radiological outcome & & & 0.53 \\
\hline Radiological union (weeks) & $7.65 \pm 1.09$ & $7.45 \pm 1.00$ & 0.61 \\
\hline Maximum radial bow (mm) & $5.76 \pm 0.39$ & $5.83 \pm 0.35$ & \\
\hline Location of maximum radial bow (\%) & $62.15 \pm 4.23$ & $62.96 \pm 3.79$ & \\
\hline
\end{tabular}

Table 3: Comparison of various complications of the patients.

\begin{tabular}{|llll|}
\hline Complications & $\begin{array}{l}\text { Plate osteosynthesis }(\mathbf{n = 2 0}) \\
(\%)\end{array}$ & $\begin{array}{l}\text { Titanium elastic nail }(\mathbf{n}=\mathbf{2 0}) \\
(\mathbf{\%})\end{array}$ & P value \\
\hline Infections & $2(10)$ & $2(10)$ & 0.99 \\
\hline Malunion & $0(0)$ & $0(0)$ & NA \\
\hline Delayed union & $0(0)$ & $0(0)$ & NA \\
\hline Synostosis & $0(0)$ & $0(0)$ & NA \\
\hline Neuropraxia & $1(5)$ & $0(0)$ & 0.48 \\
\hline Implant failure & $0(0)$ & $0(0)$ & NA \\
\hline
\end{tabular}

\section{DISCUSSION}

The present study was conducted to compare the functional and radiological outcomes in treating both bone diaphyseal forearm fractures with either PO or TEN. We observed that duration of hospital stay was significantly lower in patients in the TEN group $(44.75 \pm 6.38$ minutes $)$ as compared to those in the PO group $(69.71 \pm 5.91$ minutes), $\mathrm{p}$ value $<0.01$. Similarly, duration of hospital stay was significantly lower in patients in the TEN group (5.01 \pm 0.67 days) as compared to those in the PO group (8.32 \pm 1.44 days), $p$ value $<0.05$. In a similar study by Abdulkareem and colleagues, duration of surgery was found to be $33.4 \pm 8.3$ minutes and $47.7 \pm 8.8$ minutes in the TEN and PO group respectively. ${ }^{13}$ In concordance with the results of the present study, Abdulkareem et al also found the duration of surgery to be significantly lesser in TEN group as compared to PO group. Additionally, the authors found duration of hospitalization to be $1.65 \pm 1.11$ days and
2.66 \pm 0.96 days in the TEN and PO group respectively, with no significant difference between them. This finding is contrary to our finding, in which we found length of hospital stay to be significantly shorter among TEN patients. In another study by Topak et al, total operation time was $57.26 \pm 13.11$ minutes and $115.66 \pm 23.02$ minutes in the TEN and PO group respectively and the difference was significant ( $\mathrm{p}$ value $<0.001) .{ }^{14}$ Additionally, mean total length of hospitalization was $1.52 \pm 0.66$ days and $2.5 \pm 1.04$ days in the TEN and PO group respectively ( $\mathrm{p}$ value $<0.001)$. These two findings were similar to the findings of the present study.

We observed that functional as well as radiological outcomes were similar in patients between TEN and PO group. Topak et al also assessed functional outcomes using price index. ${ }^{14}$ They reported excellent outcomes in $76 \%$ and $77 \%$ of the patients in TEN and PO groups respectively, with no statistical significance between them. 
In addition, the authors found that mean union time was 8.14 \pm 2.74 weeks and $11.22 \pm 4.41$ weeks in the TEN and PO groups respectively. In the present study we observed mean union time of $7.45 \pm 1.00$ and $7.65 \pm 1.09$ weeks in TEN and PO groups respectively, with no statistical difference between them. In a similar study by Thapa et al, the mean union time for nail was 7.86 weeks and for the plate was 7.33 weeks. $^{15}$ No statistically significant differences were found between the groups for the union of fracture at 3 months ( $\mathrm{p}$ value $=0.780$ ). Also, the authors noted that the average maximum radial bow magnitude was $6.09 \%$ (range $4.5 \%-7.6 \%$ ), and the location was $65.14 \%$ (range $51 \%-78 \%$ ). Normal values by Firl for children are $7.21 \pm 1.03 \%$ and $60.39 \pm 3.74 \%$, respectively. There were no significant differences between both groups for the value of maximum radial bow magnitude and its location ( $\mathrm{p}$ value $=0.60$ and $\mathrm{p}$ value $>0.05$ ). Freese and colleagues reported a significant difference in the location and magnitude of the radial bow in patients treated with intra- medullary fixation relative to those treated with plate or screw fixation. ${ }^{16}$ In the nailing group the radial bow magnitude was $5.1 \%(4.8,5.4 \%)$ versus $5.9 \%(5.5,6.4 \%)$ in the ORIF group ( $\mathrm{p}$ value $=0.01$ ). In addition, the location of the maximum radial bow was more distal in the nailing group when compared to the plating group $67.9 \%(66.3$, $69.5 \%)$ versus $62.4 \%(60.1,64.8 \%)$ of the length of the radius, ( $p$ value $<0.01$ ). Furthermore, the authors reported that in the nailing group, the median time to radiographic union was 68 days (95\% CI 59-75 days) and the plating group had a median time to radiographic union of 58 days (95\% CI 46-67); (p value $=0.01)$.

We observed that there were 2 cases of infections and one case of neuropraxia in the TEN group and only 2 cases of infection in the PO group. Thus both our study groups were similar with respect to the post-operative complications. Topak et al reported that although the complications observed were different, complication rates were the same (20\% in TEN and $16 \%$ in PO group, p value $=0.052) .{ }^{14}$ They reported 2 cases of refracture and 5 cases of pin entry irritation in the TEN group and one case of surgical area infection and 2 cases of hypertrophic scar in the PO group. Thapa et al reported that the nailing group had 5 cases of superficial wound infections, 2 cases of bursitis and one case of tendon adhesion. ${ }^{15}$ Freese et al reported similar post-operative complication rate in nailing and plating group (12\% in the plating group and $29 \%$ in the nailing group, $p$ value $=0.13) .{ }^{16}$ In the similar study, Teoh et al reported that one patients in the nailing group had pin track infection causing osteomyelitis, which was successfully treated with antibiotics. ${ }^{17}$ In the plating group, one patient had an initial ulna palsy, which resolved with time. There was no significant loss of forearm motion.

\section{Limitations}

There are a few limitations of the study. First, gender could affect the union rates and due to small sample size gender wise comparison between PO and TENS groups was not possible. Second, the radiographic assessment could be subjective and could affect the radiological outcomes.

\section{CONCLUSION}

Based on the results of the present study, we conclude that both PO and TEN are be safely performed in children with diaphyseal both bone forearm fractures. In our sample, functional and radiological outcomes and complication rate were similar between the patients who underwent PO or TEN. Though we observed significantly lower duration of surgery and length of hospital stay in the TEN group, future studies are required to support our results and before one technique can be recommended over the other.

Funding: No funding sources

Conflict of interest: None declared

Ethical approval: The study was approved by the institutional ethics committee

\section{REFERENCES}

1. Landin LA. Fracture patterns in children. Analysis of 8,682 fractures with special reference to incidence, etiology and secular changes in a Swedish urban population 1950-1979. Acta Orthop Scand Suppl. 1983;202:1-109.

2. Worlock P, Stower M. Fracture patterns in Nottingham children. J Pediatric Orthop. 1986;6:656-60.

3. Bae D. Pediatric distal radius and forearm fractures. J Hand Surg. 2008;33:1911-23.

4. Patel A, Li L, Anand A. Systematic review: functional outcomes and complications of intramedullary nailing versus plate fixation for bothbone diaphyseal forearm fractures in children. Injury. 2014;45:1135-43.

5. Droll KP, Perna P, Potter J. Outcomes following plate fixation of fractures of both bones of the forearm in adults. $\mathrm{J}$ Bone Joint Surg Am. 2007;89:2619-24.

6. Henle P, Ortlieb K, Kuminack K. Problems of bridging plate fixation for the treatment of forearm shaft fractures with the locking compression plate. Arch Orthop Trauma Surg. 2011;131:85-91.

7. Sage FP. Medullary fixation of fractures of the forearm. A study of the medullary canal of the radius and a report of fifty fractures of the radius treated with a prebent triangular nail. J Bone Joint Surg Am. 1959;41:1489-516.

8. Van der Reis WL, Otsuka NY, Moroz P. Intramedullary nailing versus plate fixation for unstable forearm fractures in children. J Pediatr Orthop. 1998;18:9-13.

9. Visna P, Vlcek M, Valcha M. Management of diaphyseal forearm fractures using LCP angle- stable fixation devices and intramedullary nailing. Rozhl Chir. 2009;88:708-15. 
10. Fracture and dislocation compendium. Orthopaedic trauma association committee for coding and classification. J Orthop Trauma. 1996;10:1-154.

11. Price CT, Scott DS, Kurzner ME, Flynn JC. Malunited forearm fractures in children. J Pediatr Orthoped. 1990;10(6):705-12.

12. Firl M, Wünsch L. Measurement of bowing of the radius. J Bone Joint Surg Br. 2004;86:1047-9.

13. Abdulkareem FM, Hwaizi L. Comparative Study between Elastic Nail Versus Plates and Screws in the Treatment of Diaphyseal Both Bone Forearm Fracture in Children. Indian J Public Health Res Develop. 2020;11(2).

14. Topak D, Doğar F, Yıldız M, Bilal Ö, Şakı Ö, Ekici E. Comparison of two different surgical treatments of forearm double diaphysis fractures in adolescents. Ann Clin Anal Med. 2020;11(5):457-61.

15. Thapa UJ, Wahegaonkar K, Ranjeet N, Sapkota K, Onta PR, Thapa P. Comparative study in the outcome of intramedullary nailing to plating for both-bone forearm fracture in early and mid-adolescent age group. Medical Journal of Dr. DY Patil Vidyapeeth. 2018;11(6):499.

16. Freese KP, Faulk LW, Palmer C, Baschal RM, Sibbel SE. A comparison of fixation methods in adolescent patients with diaphyseal forearm fractures. Injury. 2018;49(11):2053-7.

17. Teoh KH, Chee YH, Shortt N, Wilkinson G, Porter DE. An age-and sex-matched comparative study on both-bone diaphyseal paediatric forearm fracture. Journal of children's orthopaedics. 2009;3(5):367-73.

Cite this article as: Barua DS, Joon A, Vaisakh A, Shirdinayak TS, Hari KNG. Comparing titanium elastic nailing and plate osteosynthesis in treating both bone diaphyseal fractures of forearm in children. Int J Res Orthop 2021;7:1117-21. 